\title{
Assessment of changes in color and color parameters of light-cured composite resin after alternative polymerization methods
}

\author{
Emine Sirin Karaarslan ${ }^{1}$ \\ Mehmet Bulbul ${ }^{2}$ \\ Ertan Ertas $^{3}$ \\ Mehmet Ata Cebe ${ }^{4}$ \\ Aslihan Usumez ${ }^{5}$
}

\section{ABSTRACT}

Objective: To examine the amount of change in color and color parameters of a composite resin (Filtek P60) polymerized by five different polymerization methods.

Methods: A Teflon mold $(6 \mathrm{~mm}$ in diameter, $2 \mathrm{~mm}$ in height) was used to prepare the composite resin discs (n=10). G1: Polymerization with inlay oven; G2: Polymerization with HQTH and autoclave; G3: Polymerization with LED and autoclave; G4: Polymerization with HQTH; G5: Polymerization with LED. Colorimetric values of the specimens before and after polymerization were measured using a spectrophotometer. The CIE L*a*b color system was used for the determination of color difference. Analysis of variance (ANOVA) was used to analyze the data for significant differences. Tukey's HSD test and paired two-tailed tests were used to perform multiple comparisons ( $a=.05)$.

Results: There were no significant differences in total color change $\left(\triangle \mathrm{E}^{*} \mathrm{ab}\right)$ among the polymerization groups $(P>.05)$. However, the lowest color change ( $\triangle E^{*}$ ab) value was 3.3 in $L E D$ and autoclave; the highest color change $\left(\triangle \mathrm{E}^{*} \mathrm{ab}\right)$ value was 4.6 in $\mathrm{HQTH}$. For all groups, $\mathrm{ClE} \mathrm{L}^{*}, \mathrm{C}^{*}$ ab and a*values decreased after polymerization $(P<.05)$. The highest $\Delta b^{*}$ and $\Delta C^{*}$ ab values were observed in specimens polymerized in an inlay oven $(P<.05)$.

Conclusions: Composite resin material showed color changes above the clinically accepted value in all study groups $\left(\Delta E^{*} a b \geqslant 3.3\right)$. All specimens became darker during investigation $\left(\Delta L^{*}<0\right)$. Specimens polymerized with inlay oven presented the highest $\Delta b^{*}$ values which means less yellow color in specimens. (Eur J Dent 2013;7:110-116)

Key words: Composite resin; color change; polymerization methods; inlay oven

1 Department of Restorative Dentistry, Faculty of Dentistry, Gaziantep University, Gaziantep, TURKIYE

2 Department of Prosthodontics, Faculty of Dentistry, Gaziantep University, Gaziantep, TURKIYE

3 Department of Restorative Dentistry, Faculty of Dentistry, Ondokuz Mayis University, Samsun, TURKIYE

4 Department of Restorative Dentistry, Faculty of Dentistry, M. Kemal University, Hatay, TURKIYE
5 Department of Prosthodontics, Faculty of Dentistry, Bezmialem Vakif University, Istanbul, TURKIYE

Corresponding author: Dr. Emine Sirin Karaarslan Gaziantep University, Faculty of Dentistry, Department of Restorative Dentistry, Kampus, Gaziantep, 27310, TURKIYE Tel: +90 3423606060 ext 76614 Fax: +90 3423610610 Email: karaarslan.eminedgmail.com 


\section{INTRODUCTION}

The importance of esthetic in dentistry is well known. ${ }^{1}$ It has been reported, for example, that esthetic dental restorative treatment can improve a patient's self-esteem. ${ }^{2}$

Initial shade matching of an uncured composite resin material to its adjacent tooth is an important clinical practice in esthetic restorative procedures, and once an appropriate match is obtained, the color match should be maintained after polymerization. However, optical properties of dental composite resins change as a result of polymerization, and the extent of change is influenced by the characteristics of the material and wavelength., ${ }^{3,4}$ Lighter or less chromatic shades tend to show higher color changes than more chromatic or darker shades. ${ }^{5}$ To compensate this color change, an initial color choice that is more yellow or more chromatic than the needed final color has been suggested in clinical applications. ${ }^{6}$

The most extensively used light source for photoactivating a composite resin material is quartz tungsten halogen (QTH) lights. ${ }^{7}$ The QTH with higher light intensities (HQTH) were introduced in dentistry. Decreasing the total cure time for adhesive and composite materials is useful for both the clinician and the patient. Additionally, higher curing light intensities may lead to superior physical and mechanical properties. ${ }^{8}$ Light-emitting diode (LED) curing lights are used to polymerize resin-based restorative materials, and their effect on the physical properties of resin-based restorative materials has been investigated. 9 Because contemporary LED lights yield superior irradiance (approximately $1,000 \mathrm{~mW} / \mathrm{cm}^{2}$ ) to QTH light lapproximately $800 \mathrm{~mW} / \mathrm{cm}^{2}$ ), LED lights are expected to polymerize resin materials as or even more effective than QTH. ${ }^{9}$

Post-cure heating of resin composite materials is a extremely popular restorative technique. This method subjects a light-cured composite inlay to an immediate heat treatment for the purpose of increasing material cure and thus enhancing clinical properties..$^{10}$ In Rueggeberg's study, the degree of color change was influenced more by the amount of resin content in the composite systems than by the particular resin composition. Microfill composite resins showed greater potential for color change than did the other types of materials. If clinicians are considering using conventional light-cured composite materials for inlays, the choice of material as well as the post-cure temperature will influence the ability to match the inlay with the initial shade of composite chosen. ${ }^{11}$ An important factor is the possibility of using postpolymerization mechanisms associated with heat, pressure, or high light intensity in indirect composite systems. ${ }^{12}$ With respect to materials, indirect and direct composites have similar compositions. ${ }^{13}$ Currently, easy and inexpensive techniques have been enhanced for direct composites in indirect restorations. Coupled with the use of devices that are always found in dentists' offices to apply these techniques, better performance can now be obtained and harnessed from material properties, resulting in improved dental health. ${ }^{14}$

Presently, electronic shade-matching instruments have been used for dental practice. ${ }^{15}$ In order to determine objectively the color changes on composite restorations, some methods have been experienced, among them the spectrophotometry, which makes the study of several parameters related to color stability of composite resins possible. In this method reflected wavelength by a body is changed in values expressed in $\Delta \mathrm{E}^{*}$ units. The $\Delta \mathrm{E}^{*}$ values can be used so that present the color changes provided by the composite resin after treatment or period of time. ${ }^{16}$ Instrumental color analysis offers a potential advantage over visual color determination, as instrumental readings are objective, quantifiable, and more rapidly obtainable. ${ }^{17}$

The Comission Internationale de l'Eclairage Lab (CIE L*a*b) color system has been used for determination of color difference. ${ }^{18-21}$ Chroma is calculated as $\mathrm{C}^{*} a b=\left(a^{* 2}+b^{* 2}\right)^{1 / 2.4}$ The total color difference $\Delta \mathrm{E}^{*}$ ab between two color stimuli, each given in terms of $\mathrm{L}^{*}, \mathrm{a}^{*}, \mathrm{~b}^{*}$ is calculated from: ${ }^{22} \Delta \mathrm{E}^{*} a b$ $=\left[\left(\Delta L^{*}\right)^{2}+\left(\Delta a^{*}\right)^{2}+\left(\Delta b^{*}\right)^{2}\right]^{1 / 2}$.

The $L^{*}$ coordinate is a measure of the lightness-darkness of the specimen. The greater the $L^{*}$ is, the lighter the specimen. The $a^{*}$ coordinate is a measure along the red-green axis. A positive a* relates to the amount of redness, and a negative $a^{*}$ relates to greenness of a specimen. The $b^{*}$ coordinate is a measure along the yellow-blue axis, that is a positive $b^{*}$ relates to the amount of yellowness; a negative $b^{*}$ relates to the amount of blueness of the specimen. $\Delta \mathrm{L}^{*}, \Delta \mathrm{a}^{*}$ and $\Delta \mathrm{b}^{*}$ are the differences in the CIE color-space parameters of the 2 colors. ${ }^{23}$ 
Threshold color difference levels based on instrumental color measurements that can be visually perceivable or clinically acceptable have been discussed. However, the clinically acceptable value for color difference in restorative materials is assumed to be $\Delta \mathrm{E}^{*} \leqslant 3.3 .^{24}$

The aim of this in vitro study was to investigate the amount of change in color and color parameters of composite resin material (Filtek P60, 3M ESPE) polymerized by five different polymerization methods. The null hypothesis of the present study were that (1) the polymerization methods don't affect the color parameters of composite resin material, (2) there is no color difference between unpolymerized and polymerized composite resin regarding the polymerization methods.

\section{MATERIALS AND METHODS}

The composite resin used in this study was Filtek P60 (color A3; 3M ESPE, St. Paul, U.S.A.) packable light-cured composite. A $6 \mathrm{~mm}$ diameter hole was made in a $2 \mathrm{~mm}$ high Teflon plate and filled with composite resin. After inserting the composite resin material into the Teflon plate, a strip was laid on the top of the specimens and the color of the composite specimens before polymerization was measured on stripped surfaces. Five groups were considered for color change $(n=10)$ (Table 1).

Group I: Polymerization with inlay oven (Tescera ATL, Bisco, USAl for 15 minutes.

Group II: Conventional polymerization with HQTH unit (High Quartz Tungsten Halogen Blue Luxer, Monitex, Taipei, Taiwan) at $740 \mathrm{~mW} / \mathrm{cm}^{2}$ for 30 seconds and post-polymerized in an autoclave (Europa B xp, Tecno-gaz, Italy) at 30 PSI pressure, $134^{\circ} \mathrm{C}$ heat for 17 minutes.

Group III: Conventional polymerization with LED unit (Light-Emitting Diode Demi, Kerr, Orange, USAl at $1100 \mathrm{~mW} / \mathrm{cm}^{2}$ for 20 seconds and post-polymerized in an autoclave (Europa $B \mathrm{xp}$, Tecno-gaz, Italyl at $30 \mathrm{PSI}$ pressure, $134^{\circ} \mathrm{C}$ heat for 17 minutes.

Group IV: Conventional polymerization only with HQTH unit (Blue Luxer, Monitex, Taipei, Taiwan) at $740 \mathrm{~mW} / \mathrm{cm}^{2}$ for 30 seconds.

Group V: Conventional polymerization only with LED unit (Demi, Kerr, Orange, USA) at $1100 \mathrm{~mW}$ / $\mathrm{cm}^{2}$ for 20 seconds.

The plate was reversed so that the lower side of the plate was on top. The composite was once again irradiated for the same irradiation times. The characteristics, polymerization times, and polymerization protocols of the light-curing units, inlay oven, and autoclave used are shown in Table 1. After polymerization, no polishing techniques were used in order to avoid modification of the surfaces, which could influence the results. ${ }^{25}$

Colorimetric values of the composite resin specimens before and after polymerization were measured using a spectrophotometer (Vita EasyShade, Vident, No: 502744, USA). The spectrophotometer comprises a base unit and a handpiece. In this system, the specimen was exposed to an emission of light, and the reflected light was analyzed with a spectrophotometer. Instrument calibration was evaluated after measurement of each group $(n=10)$ and recalibration. The tip of the handpiece was placed firmly into the calibration port and was held steadily in place until the instrument sounded a beep to indicate that calibration was complete. The measuring tip of the spectrophotometer was a circle $5 \mathrm{~mm}$ in diameter. Color measurement was performed in consecutive tests on central parts of the specimens. Specimens were positioned at the same place on different occasions to ensure consistency of the repeated measurements. A white plate was used for the background color in this study. ${ }^{22,26}$ All specimens were chromatically measured three times, and the average values were

Table 1. Prortocols of polymerization in this study.

\begin{tabular}{|c|c|c|c|c|}
\hline Groups & $\begin{array}{c}\text { Polymerization } \\
\text { type }\end{array}$ & Curing unit & Manufacturer & $\begin{array}{l}\text { Polymerization } \\
\text { time }\end{array}$ \\
\hline Group I & Inlay oven & Tescera inlay oven & Bisco, USA & $15 \mathrm{~min}$ \\
\hline Group II & HQTH unit and autoclave & Blue Luxer and Europa B xp & $\begin{array}{c}\text { Monitex, Taiwan and Tecno- } \\
\text { gaz, Italy }\end{array}$ & $30 \mathrm{sn}$ and $17 \mathrm{~min}$ \\
\hline Group III & LED unit and autoclave & Demi led and Europa B xp & Kerr, USA and Tecno-gaz, Italy & $20 \mathrm{sn}$ and $17 \mathrm{~min}$ \\
\hline Group IV & HQTH unit & Blue Luxer & Monitex, Taiwan & $30 \mathrm{sn}$ \\
\hline Group V & LED unit & Demi led & Kerr, USA & $20 s n$ \\
\hline
\end{tabular}


calculated. CIE L*a*b color system was used for determination of color difference. Changes in color coordinates $\left(\Delta \mathrm{L}^{*} \Delta \mathrm{a}\right.$ and $\left.\Delta \mathrm{b}^{*}\right)$ were calculated as 'the value after polymerization - the value before polymerization'. The formula of $\Delta \mathrm{E}^{*} \mathrm{ab}$ :

$\Delta E^{*} a b=\left[\left(\Delta L^{*}\right)^{2}+\left(\Delta a^{*}\right)^{2}+\left(\Delta b^{*}\right)^{2}\right]^{1 / 2}$.

Chroma was calculated as $C^{*} a b=\left(a^{* 2}+b^{* 2}\right)^{1 / 2}$.

\section{Statistical analysis}

The data were entered into a spreadsheet (Excel; version 4.0, Microsoft, Seattle, WA, USA) for calculation of descriptive statistics. Analysis of variance (ANOVA) was used to analyze the data for significant differences. Tukey's HSD test and paired two-tailed tests were used to perform multiple comparisons ( $a=.05)$. The data were analyzed with the SPSS 13 for Windows statistical program software (SPSS Inc., Chicago, IL, USA).

\section{RESULTS}

Colorimetric values of composite resin after polymerization are listed in Table 2. There were noticeable color changes in all groups $\left(\Delta E^{*} a b \geqslant\right.$ 3.3). The range of changes in composite resin according to polymerization methods was 3.3-4.6 in color ( $\Delta \mathrm{E}^{*}$ ab: distribution span: 1.2 ), -1.0 to-1.6 in $\Delta \mathrm{L}^{*}$ (distribution span: -0.6 ), -1.5 to -2.8 in $\Delta \mathrm{C}^{*}$ ab (distribution span: -1.3 ), -4.0 to -2.6 in $\Delta a^{*}$ (distribution span:-1.4), -1.7 to -0.5 in $\Delta b^{*}$ (distribution span: -1.2). There were no significant differences in color change among the groups $(P>.05)$.

There were no significant differences in CIE $L^{*}$ value $(P>.05)$ among the groups. $C^{*}$ ab value was affected by polymerization methods $(P<.05)$. There were significant differences between the inlay oven and the other four groups $(P<.05)$. While the lowest $\Delta C^{*}$ ab value was observed in polymerization with LED and autoclave, the highest $\Delta C^{*}$ ab value was observed in polymerization with the inlay oven. Also, there were significant differences between polymerization with LED and autoclave and the HQTH light curing unit $(\mathrm{P}<.05)$. The CIE a* value was not affected by polymerization methods. The CIE a* value shifted toward green $\left(\Delta a^{*}<0\right)$. But, there were no significant differences among groups ( $P>$.05). The CIE $b^{*}$ value was affected by polymerization methods $(\mathrm{P}<.05)$. The CIE $b^{*}$ values of the inlay oven polymerization group is significantly differences from the other four groups $(\mathrm{P}<.05)$. The composite resins polymerized with the inlay oven showed the highest $\Delta^{*}$ b values which means less yellow color in specimens.

For all groups, CIE L* values decreased after polymerization, all specimens became darker during investigation $\left(\Delta L^{*}<0\right)$. In all groups, $C^{*} a b$ and $\mathrm{CIE} \mathrm{a}^{*}$ values decreased after polymerization $(P<.05)$. The $C I E$ a* value shifted toward green $\left(\triangle a^{*}<0\right)$. CIE $b^{*}$ values decreased after polymerization $\left(\Delta b^{*}<0\right)$, indicating the increase of blue color and the decrease of yellow color factor $(P<.05)$. There were significant differences b1 and b0 lafter and before) in the inlay oven polymerization group, LED and autoclave, LED, and HQTH $(\mathrm{P}<.05)$.

Mean changes in color and color parameters by the polymerization methods are presented in Figure 1.

\section{DISCUSSION}

This in vitro study measured the amount of the changes in color and color parameters of composite resin material polymerized by five different polymerization methods. Based on the results of the present study, the first null hypothesis of the present study that the polymerization methods don't affect the color parameters of composite resin material was partially accepted because color change was not affected by polymerization methods. However, $C^{*} a b$ and $b^{*}$ values were affected by polymerization methods. The second null hypothesis that there is no color difference between unpolymerized and polymerized composite resin regarding the polymerization methods

Table 2. Changes in color and color parameters after polymerization.

\begin{tabular}{|c|c|c|c|c|c|}
\hline Polymerization Methods & $\Delta \mathrm{E}^{*} \mathrm{ab}$ & $\Delta \mathrm{C} * \mathrm{ab}$ & $\Delta \mathrm{L}^{*}$ & $\Delta a^{*}$ & $\Delta \mathrm{b}^{*}$ \\
\hline Inlay oven & $4,2(0.6) a$ & $-2.8 \quad(0.3)$ & $-1.6(0.5)$ & $-3.4(0.7)$ & $-1.7(0.4)$ \\
\hline HQTH unit and autoclave & $3,8(1.2)$ & $-1.6(0.3)$ & $-1.1(1.0)$ & $-3.4(1.5)$ & $-0.5(0.7)$ \\
\hline LED unit and autoclave & $3,3(1.4)$ & $-1.5(0.3)$ & $-1.0(1.7)$ & $-2.6(1.5)$ & $-0.7(0.5)$ \\
\hline HQTH unit & $4,6(0.5)$ & $-1.8(0.4)$ & $-1.3(1.9)$ & $-4.0(0.9)$ & $-0.5(0.5)$ \\
\hline LED unit & $3,9(1.2)$ & $-1.9(0.4)$ & $-1.4(1.0)$ & $-3.4(1.0)$ & $-0.8(0.4)$ \\
\hline
\end{tabular}

aValues in parentheses indicate standard deviation 
was accepted. The results of the present study demonstrated that there were color changes in all groups. $\Delta E^{*}$ ab values of specimens were $\geqslant 3.3$. The lowest color change $\left(\Delta E^{*} a b\right)$ value was 3.3 in polymerization with LED and autoclave; the highest color change $\left(\Delta E^{*} a b\right)$ value was 4.6 in polymerization with $\mathrm{HQTH}$.

The polymerization color changes of resin composites were investigated, and the range of color change was 2.6-4.1. $\Delta \mathrm{E}^{*}$ ab units depended on the shade. ${ }^{27}$ Changes in CIE L* parameter (lightness) after polymerization were significant for all materials, and changes in the lightness had the greatest influence on polymerization color change. ${ }^{27}$ In the current study, Filtek P60 A3 shade composite resin was used. There were no significant differences in $\Delta E^{*}$ ab value among the groups. In all groups, CIE $L^{*}$ value decreased after polymerization, but there were no significant differences among the groups. Further in vitro study on this subject should be performed.

Filtek $^{\mathrm{TM}} \mathrm{P} 60$ restorative material is a visible light-activated, radiopaque, restorative composite designed for use in posterior restorations. According to the manufacturer's instructions, Filtek ${ }^{\text {TM }}$ P60 composite resin material is indicated for use in indirect restorations including inlays, onlays and veneers. Thus, in the current study we polymerized this composite resin material in inlay and light sources followed by additional time in an autoclave.

Light sources have been used to convert the

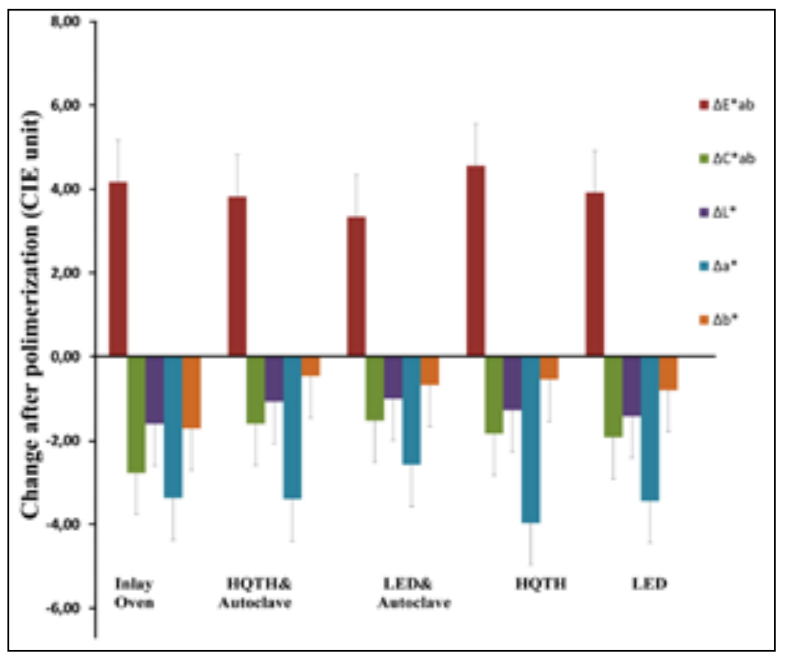

Figure 1. Mean changes in color parameters by the brand of resin composites. composite, and have been investigated whether there is a correlation between the intensity of light source, time of exposure, types of material, and distance from the tooth to the curing source. ${ }^{28}$ Light-sensitive materials contain camphorquinone (CQ) to react with a reducing agent when activated, and activating it to polymerization requires sufficient light intensity and a suitable wavelength. ${ }^{29}$ $C Q$ significantly influences the color of the material $^{30}$ as it is a yellow chemical compound. During light irradiation at $478 \mathrm{~nm}$ wavelength, it changes color and becomes colorless. However, if irradiation is not enough, a certain amount of yellow will remain. ${ }^{31}$ In the present study, specimens polymerized with different polymerization units revealed a color shift from yellow to blue $\left(\Delta b^{*}<0\right)$ and from red to green $\left(\Delta a^{*}<0\right)$ after polymerization. All specimens became darker during investigation $\left(\Delta \mathrm{L}^{*}<0\right)$. The same phenomenon, in term as decrease in $b^{*}$ value after resin composite polymerization was also reported by Sidhu et al. ${ }^{32}$

It is well known that inadequate polymerization adversely affects the mechanical properties of composite materials in terms of strength, color stability, ${ }^{29}$ hardness, ${ }^{12}$ and wear resistance. ${ }^{33}$ When post-polymerization methods are used, material properties can be improved. ${ }^{14}$ Post-cure heating of resin composite materials has become a very popular restorative technique. ${ }^{34}$ Many properties enhanced by post-cure heating, such as fracture toughness, flexural modulus, and flexural strength, were found to decrease to levels identical to those of the light-cured-only group ${ }^{35}$ when the specimens were subjected to water storage after curing. The various methods of post-curing (light, heat, pressure, vacuum, and nitrogen) allow for secondary curing of the composite by increasing the conversion of the resin material from monomer to polymer. ${ }^{36}$ In their research, Silva et al $^{37}$ used different laboratory photo curing units and conventional halogen light sources followed by additional in an autoclave. They reported that the use of light curing in conjunction with heat and pressure curing improved the mechanical properties of resin composites and the use of alternative polymerization with conventional photo curing; the autoclave was shown to be feasible, with a wide 
implication for the general public in terms of reduced dental treatment cost. The amount of color changes of composite resin material polymerized by inlay oven and light sources followed by additional time in an autoclave was evaluated in the current study. But, there were no significant differences in color change among groups.

The polymerization process in Indirect Inlay System (Tescera ATL, Bisco, USA) combines two curing mechanisms: light and heat under water. After complete development of the restoration, the final cure is accomplished in a heat cup with the restoration submerged in water. ${ }^{38,39}$ In the current study, CIE b* value (yellow-blue) decreased after polymerization. The composite resins that polymerized with inlay oven showed the highest $\Delta^{*}$ b values which means less yellow color in specimens. The CIE *b values of the polymerization inlay oven is significantly different from the other four groups. The highest $\Delta \mathrm{C}^{*}$ ab values were observed in specimens polymerized in an inlay oven. In this inlay system, the final cure is accomplished in a heat cup with the restoration submerged in water. Therefore, the highest $\Delta^{*} \mathrm{~b}$ and $\Delta \mathrm{C}^{*}$ ab values may be observed in this polymerization system. Further in vitro study on this subject should be performed.

Polymerized composite resins tend to have greater diffuse reflectance than unpolymerized composite resins. This alteration reflects the increase of refractive index of the resin phase associated with monomer conversion (into polymer) of monomer mixtures, while refractive index of the filler remains unchanged. ${ }^{3}$ Lee and Powers ${ }^{40}$ reported that lightness (CIE $L^{*}$ ) increased or decreased depending on the material and shade after polymerization. In their study, Kim and Lee ${ }^{4}$ reported that CIE $L^{*}$ values decreased after polymerization except one composite resin.

A study by Marais et $\mathrm{al}^{41}$ has suggested that power density (irradiance) does not have an effect on conversion of composite resin at depths beyond $2 \mathrm{~mm}$; because of this, in the current study, specimen thickness was $2 \mathrm{~mm}$. The specimens were cured from both sides, effectively reducing thickness of resin being cured to $1 \mathrm{~mm}$ to get maximum conversion. Tak et $\mathrm{al}^{22}$ used $2 \mathrm{~mm}$-thick specimens. In the previous study, the specimen thickness was
$1 \mathrm{~mm} .{ }^{4}$ The difference in thickness may influence the amount of color change after polymerization.

\section{CONCLUSIONS}

Within the limitations of this in vitro study, the following conclusions were drawn:

- The color changes of composite resin material in all groups were above the clinically acceptable value $\left(\Delta E^{*} a b \geqslant 3.3\right)$. There were no significant differences in total color change among the groups.

- All specimens became darker during investigation $\left(\Delta L^{*}<0\right)$.

- The composite resins that polymerized with inlay oven showed the highest $\Delta^{*} b$ values which means less yellow color in specimens.

\section{REFERENCES}

1. Carlsson GE, Wagner IV, Odman P, Ekstrand K, MacEntee M, Marinello C, Nanami T, Ow RK, Sato H, Speer C, Strub JR, Watanabe T. An international comparative multicenter study of assessment of dental appearance using computeraided image manipulation. Int J Prosthodont 1998;11:246254.

2. Davis LG, Ashworth PD, Spriggs LS. Psychological effects of aesthetic dental treatment. J Dent 1998;26:547-254.

3. Taira M, Okazaki M, Takahashi J. Studies on optical properties of two commercial visible-light-cured composite resins by diffuse reflectance measurements. J Oral Rehabil 1999;26:329-337.

4. Kim IJ, Lee YK. Changes in color and color parameters of dental resin composites after polymerization. J Biomed Mater Res B Appl Biomater 2007;80:541-546.

5. Schulze KA, Marshall SJ, Gansky SA, Marshall GW. Color stability and hardness in dental composites after accelerated aging. Dent Mater 2003;19:612-619.

6. Seghi RR, Gritz MD, Kim J. Colorimetric changes in composites resulting from visible-light-initiated polymerization. Dent Mater 1990;6:133-137.

7. Knezevic A, Tarle Z, Meniga A, Sutalo J, Pichler G, Ristic M. Degree of conversion and temperature rise during polymerization of composite resin samples with blue diodes. $J$ Oral Rehabil 2001;28:586-591.

8. Rueggeberg F. Contemporary issues in photocuring. Compend Contin Educ Dent Suppl 1999;25:4-15.

9. Mobarak E, Elsayad I, Ibrahim M, El-Badrawy W. Effect of LED light-curing on the relative hardness of tooth-colored restorative materials. Oper Dent 2009;34:65-71. 
10. Ferracane JL. Correlation between hardness and degree of conversion during the setting reaction of unfilled dental restorative resins. Dent Mater 1985;1:11-14.

11. Rueggeberg FA, Harvey DK, Evans AL. Color changes in post-cure heat-treated resin composites. Am J Dent 1991;4:171-176.

12. Tanoue N, Atsuta M, Matsumura H. Properties of a new photo-activated composite polymerized with three different laboratory photo-curing units. J Oral Rehabil 2003;30:832836 .

13. Tanoue N, Matsumura $H$, Atsuta M. Properties of four composite veneering materials polymerized with different laboratory photo-curing units. J Oral Rehabil 1998;25:358-364.

14. Soares CJ, Pizi EC, Fonseca RB, Martins LR. Mechanical properties of light-cured composites polymerized with several additional post-curing methods. Oper Dent 2005;30:389-394.

15. Paul S, Peter A, Pietrobon N, Hammerle $\mathrm{CH}$. Visual and spectrophotometric shade analysis of human teeth. $J$ Dent Res 2002;81:578-582

16. 22. Vita Easyshade Operating Manual Date of Issue: 05-05 Bad Sackingen, Germany

17. Culpepper WD. A comparative study of shade-matching procedures. J Prosthet Dent 1970;24:166-173.

18. Inokoshi S, Burrow MF, Kataumi M, Yamada T, Takatsu T. Opacity and color changes of tooth-colored restorative materials. Oper Dent 1996;21:73-80.

19. Celik C, Yuzugullu B, Erkut S, Yamanel K. Effects of mouth rinses on color stability of resin composites. Eur $J$ Dent 2008;2:247-253.

20. Hafez R, Ahmed D, Yousry M, El-Badrawy W, El-Mowafy 0. Effect of in-office bleaching on color and surface roughness of composite restoratives. Eur J Dent 2010;4:118-127.

21. Lindsey DT, Wee AG. Perceptibility and acceptability of CIELAB color differences in computer-simulated teeth. $J$ Dent 2007; 35:593-599.

22. Tak O, Altintas SH, Ozturk N, Usumez A. Effect of tree types of light-curing units on 5-year colour changes of lightcured composite. Clin Oral Investig 2009;13:29-35.

23. Knispel G. Factors affecting the process of color matching restorative materials to natural teeth. Quintessence Int $1991 ; 22: 525-531$

24. Ruyter IE, Nilner K, Moller B. Color stability of dental composite resin materials for crown and bridge veneers. Dent Mater 1987;3:246-251.

25. Hosoya Y. Five-year color changes of light-cured resin composites: influence of light-curing times. Dent Mater 1999; 15:268-274.
26. Sarac D, Sarac YS, Kulunk S, Ural C, Kulunk T. The effect of polishing techniques on the surface roughness and color change of composite resins. J Prosthet Dent 2006;96:33-40

27. Johnston WM, Hesse NS, Davis BK, Seghi RR. Analysis of edge-losses in reflectance measurements of pigmented maxillofacial elastomer. J Dent Res 1996;75:752-760.

28. Lee YK, Lim BS, Kim CW. Influence of illuminating and viewing aperture size on the color of dental resin composites. Dent Mater 2004;20:116-123.

29. Vichi A, Ferrari M, Davidson CL. Color and opacity variations in three different resin-based composite products after water aging. Dent Mater 2004;20:530-534.

30. Dlugokinski MD, Cauguman FW, Rueggeberg FA. Assessing the effect of extraneous light on photoactivated resin composites. J Am Dent Assoc 1998;129:1103-1109.

31. Tyas MJ. Colour stability of composite resins: A clinical comparison. Aust Dent J 1992;37:88-90.

32. Sidhu SK, Ikeda T, Omata Y, Fujita M, Sano H. Change of color and translucency by light curing in resin composites. Oper Dent 2006;31:598-603.

33. Ekfeldt A, Oilo G. Occlusal contact wear of prosthodontic materials. An in vivo study. Acta Odontol Scand 1988;46:159169.

34. Asmussen E. Restorative resins: hardness and strength vs. quantity of remaining double bonds. Scand $J$ Dent Res 1982;90:484-489.

35. Ferracane JL, Hopkin JK, Condon JR. Properties of heat-treated composites after aging in water. Dent Mater 1995; 11:354-358

36. Bagis YH, Rueggeberg FA. The effect of post-cure heating on residual, unreacted monomer in a commercial resin composite. Dent Mater 2000;16:244-247.

37. da Silva GR, Simamoto-Junior PC, da Mota AS, Soares CJ. Mechanical properties of light-curing composites polymerized with different laboratory photo-curing units. Dent Mater $J$ 2007;26:217-223.

38. Terry DA, Leinfelder KF. Development of a Processed Composite Resin Restoration: Preparation and Laboratory Fabrication-Part I. International Dentistry Sa 2006;8:12-20.

39. Shellard E, Duke ES. Indirect composite resin materials for posterior applications. Compend Contin Educ Dent 1999;20:1166-1171.

40. Lee YK, Powers JM. Color and optical properties of resinbased composites for bleached teeth after polymerization and accelerated aging. Am J Dent 2001;14:349-354.

41. Marais JT, Dannheimer MF, Germishuys PJ, Borman JW. Depth of cure of light-cured composite resin with light-curing units of different intensity. J Dent Assoc S Afr 1997;52:403-407. 